\title{
Neurocognitive Disorders in Coronarian Surgery and Place of the Mini Mental State Examination (MMSE)
}

\author{
Sandra Ait Aoudia* \\ Central Army Hospital, Africa
}

Submission: September 23, 2017; Published: December 13, 2017

*Corresponding author: Sandra Ait Aoudia, Medical ICU, Central Army Hospital, Algeria, Africa, Email: sandrait2004@hotmail.com

Abstract

Introduction: Neurocognitive disorders after cardiac surgery are frequent and variable in their expression. In addition to perioperative stroke, cognitive impairment occurs in $30-70 \%$ of cases, most often functional and transient. They are detected on the clinic and by specific neuropsychic tests.

Patients and methods: Prospective study, including 37 patients operated on by coronary artery bypass graft surgery. The Mini Mental State Examination (MMSE) exploring cognitive functions was performed pre- and postoperatively (J3 post-op). The loss of 2 points or more suggests a neurocognitive disorder.

Results: Average age of our patients is 63 years \pm 7.39 [44-74 years] with a sex ratio of 4.28 (30M/07W), post-operative: Calm awakening found in $67.56 \%$ of our patients, agitation in $24.32 \%$, temporo-spatial disorientation in $5.40 \%$ and ischemic stroke in $5.40 \%$ of patients.

Results of the MMSE: There are, memory impairment in 19 patients, calculation-Caution: 14 patients, orientation (time-space): 07 patients and praxia in 03 patients.

Discussion: The most affected population of neurocognitive disorders is in patients of advanced age ( $>60$ years), stroke is found in $5.4 \%$ of cases and neurocognitive disorders in $57.57 \%$, the most cognitive function often affected is memory. The factors favoring the onset of neurocognitive disorders are: Advanced age and duration of aortic clamping. The origin of neurocognitive disorders after coronary artery bypass graft surgery is multifactorial. In addition to patient-related factors, there are factors related to CEC and surgical procedure.

Conclusion: Neurocognitive complications after coronary artery surgery remain a worrying problem that could be aggravated given the increasing age of patients and the greater number of associated pathologies. The search for cognitive impairment should be an integral part of the pre- and post-operative evaluation of cardiac surgery patients. The Mini Mental State Examination (MMSE) would represent "the thermometer of cognitive function".

Keywords: Coronary Surgery; Neurocognitive Disorders; Mini Mental State Examination; Extracorporeal Circulation

\section{Introduction}

Neurocognitive disorders are the most frequent complication in cardiac surgery with extracorporeal circulation (CEC) [1]. Their incidence varies from 30 to $70 \%$ according to the studies [2-6]. The existence of these postoperative neurocognitive dysfunctions has been a phenomenon known for many years, and so many studies have focused on perioperative periods of cardiac and vascular surgery. However, these dysfunctions have also been described during noncardiac surgeries and minor surgeries [7].

Progress in both anesthesia and surgery and CEC procedures has been accompanied by a reduction in morbidity and mortality that pushes age limits. Elderly patients with multiple pathologies benefiting more and more frequently from this type of surgery are the preferred target of postoperative neurocognitive disorders, the clinical consequences of which in terms of morbidity, mortality, postoperative rehabilitation [8] and the implications are far from negligible [3].

Morbidity and mortality in cardiac surgery is established through recognized specific scores such as Euroscore or Parsonnet score where only stroke, widely studied in cardiac surgery, is clearly taken into account as a postoperative neurological complication.

Roach divided into 2 groups the neurological manifestations occurring after cardiac surgery:

I. Type I: includes stroke, TIA (Transient Ischemic Attack) and Comas. These are disorders of consciousness related to focal ischaemias of the cerebral parenchyma. Their incidence varies between 1.5 and $5.2 \%$ [9]. 
II. Type II: Represented by neuropsychological or cognitive dysfunctions (confusion, agitation, disorientation, memory disorders), found in 30 to $70 \%$ of the patients operated in cardiac surgery [10]. They are, in most cases, functional and transitory; without detectable organic lesion, detected on the clinic and by specific neuropsychic tests.

\section{Mini Mental State Examination (MMSE)}

Accurately encrypting the incidence of postoperative cognitive dysfunction requires the use of easy-to-use, sensitive and specific diagnostic tools. Many cognitive assessment tests have been proposed to detect early symptoms reliably and reliably. For example, the Mini Mental State Examination (MMSE) has been validated specifically for the detection of major disorders of major cognitive functions (orientation, registration, attention and calculation, memory, language and praxis) after cardiac surgery. Established in 1975 by Folstein [11], it is an instrument for assessing the cognitive functions developed for rapid screening. Its ease of use, speed of execution (5-10mns) as well as the extensive functions explored quickly imposed it amongst the brief evaluation instruments of functions worldwide.

Some authors suggest discussing cognitive function monitoring rather than establishing arbitrary criteria for cognitive dysfunction [12] (Figure 1).

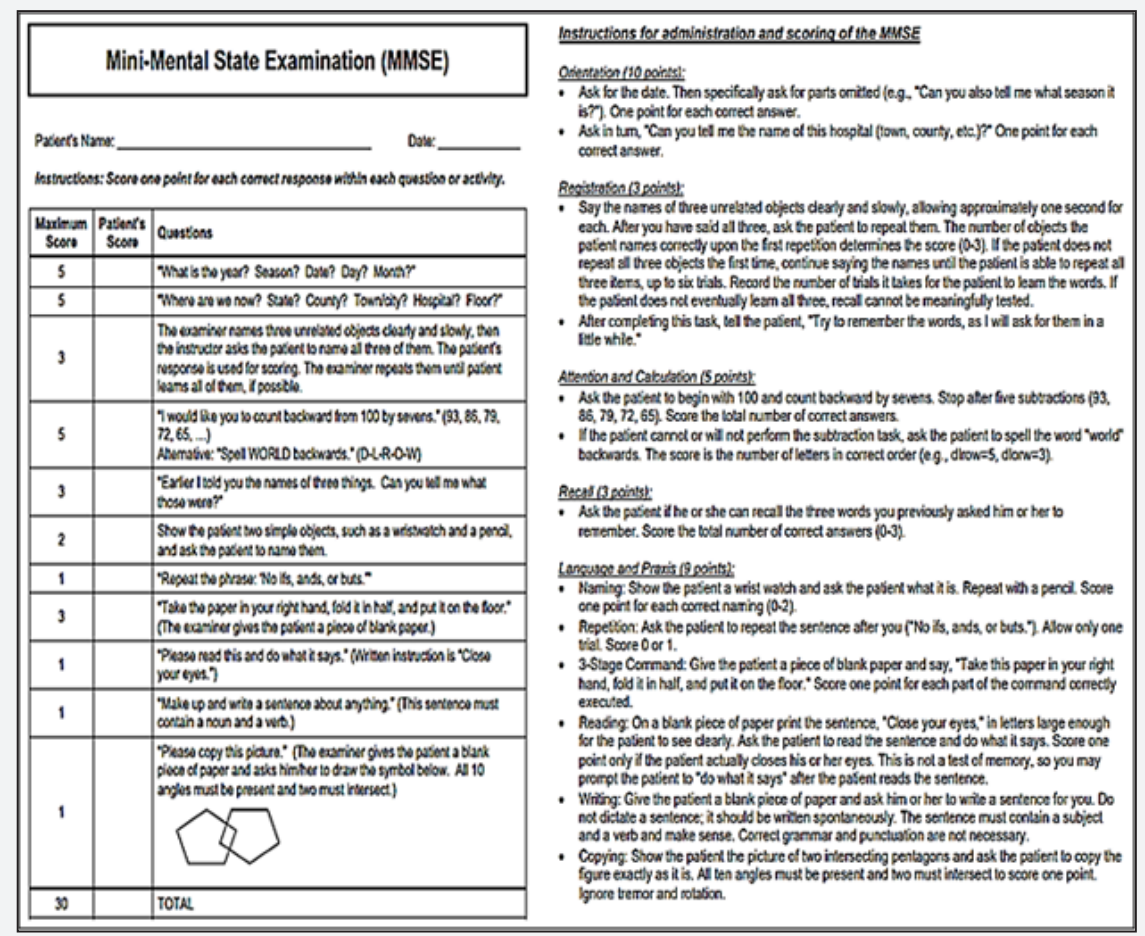

Figure 1: We can see the transverse process and the three muscle layers. Local anesthetic spreading above and below the ESP.

\section{Patients and Methods}

Our study included 37 adult patients operated for aortocoronary bypass surgery. The exclusion criteria were: Combined surgery (valve, carotid); neurological history (stroke, transient ischemic cerebral accident, epilepsy, Parkinson ...); Surgery with heart beating and patients intubated more than $24 \mathrm{~h}$ in postoperative.

The anesthetic protocol involved induction a classical sequence associating hypnovel/etomidate or propofol, sufentanil, rocuronium. The maintenance was provided by isoflurane and/ or a continuous infusion of propofol associated with a continuous infusion of sufentanil. Patients were all admitted to the intensive care unit where they received sedation a few hours before waking and extubation. The evaluation of pre- and post-operative cognitive functions involved the Mini Mental State Examination.
The test consisted of a series of questions grouped into seven categories. These questions included: orientation in time (5 points), orientation in space (5 points), immediate recall of three words ( 3 points), attention ( 5 points), delayed recall three words ( 3 points), language ( 8 points) and constructive praxis (1 point). The maximum possible score was therefore 30 points [8]. Patients were evaluated on the day before surgery and on the third postoperative day. The pre- and postoperative examiner was the same.

The statistical study carried out by Epi info 7 logicel. The quantitative variables are expressed as mean +/- standard deviations and compared using a reduced deviation test and the qualitative variables are expressed in absolute values and in percentages; the comparisons use the chi-square test. The significance threshold is defined as $\mathrm{p}<0.05$. 


\section{Results}

The 37 patients operated for coronary surgery had an average age of $63.46 \pm 7.39$ (range: 44 and 74 years), a sex ratio of $4.28(30 \mathrm{H} / 07 \mathrm{~F})$. More than half of our patients were obese with a history of hypertension, angina, dyslipidemia and diabetes (Figure 2). For preoperative therapy, antiplatelet agents are found in all our patients, Conversion enzyme inhibitors and $§$ blockers in more than $80 \%$ of our patients (Figure 3 ).

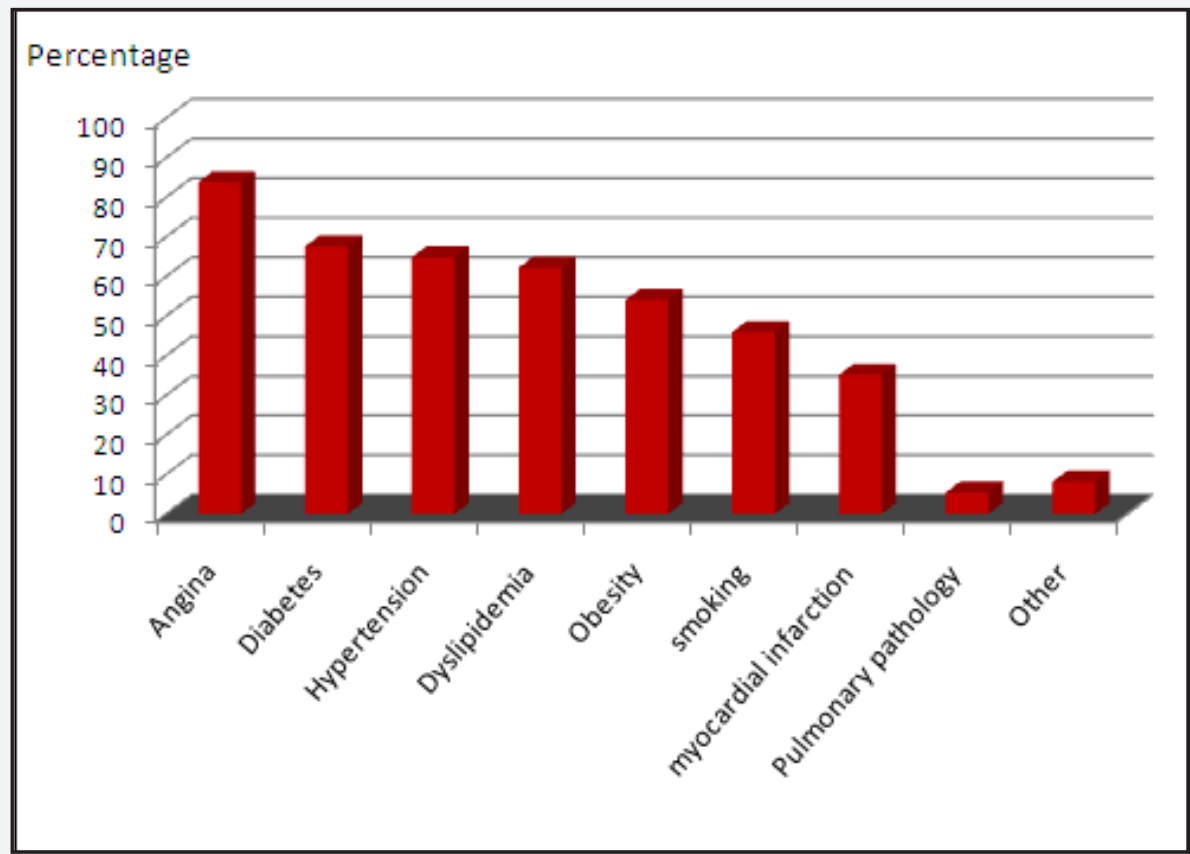

Figure 2 : Medical history and risk factors.

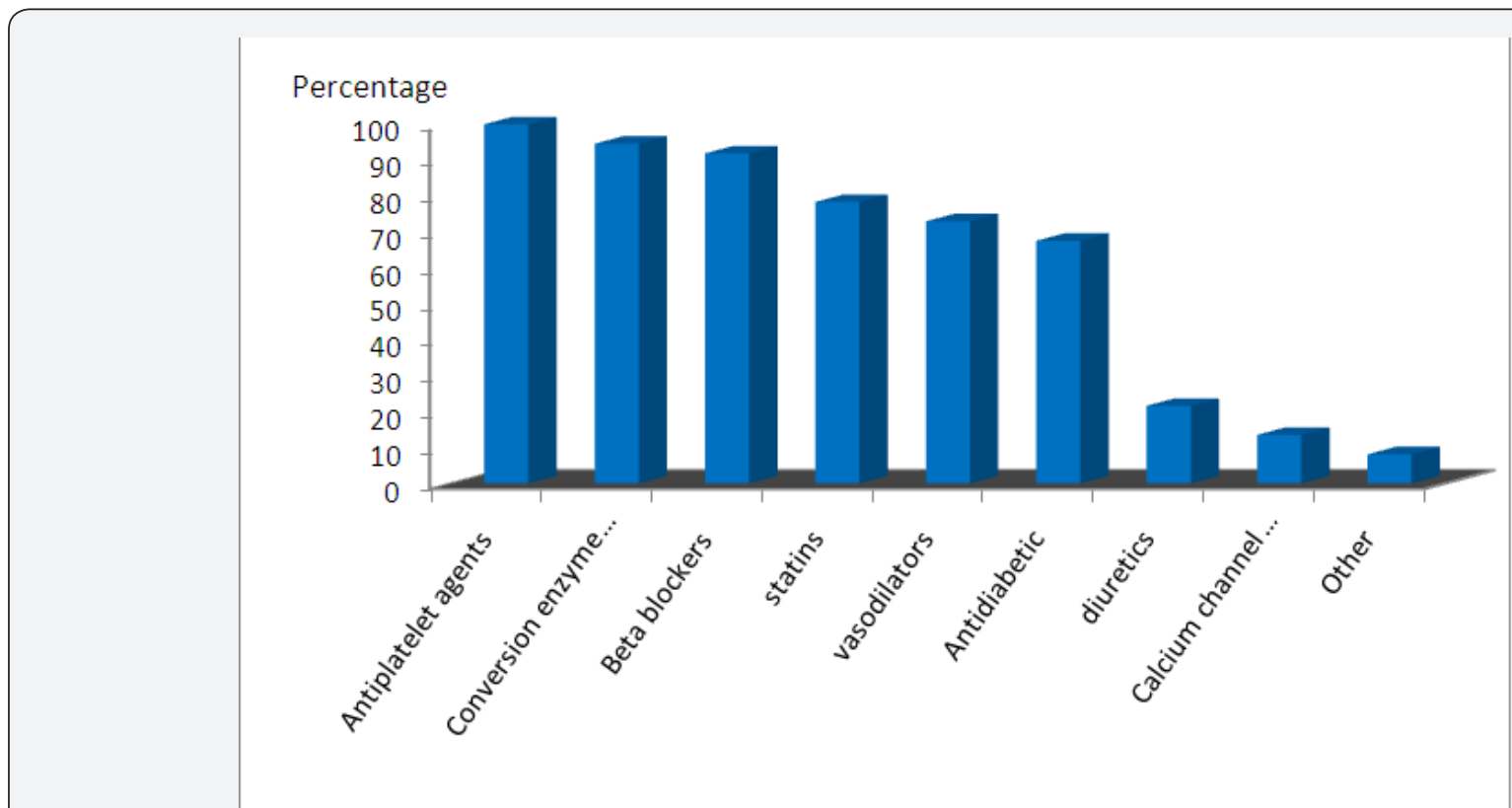

Figure 3 : Preoperative Therapeutics.

Of the 37 patients operated on for coronary surgery, only 33 patients were selected for our study, as 02 patients required a ventilation time of $>24 \mathrm{~h}$ and 02 patients were never extubated (Table 1).
A postoperative decrease in the MMSE test was two or more points in 19 patients (57.57\%). The decline in performance affected all items (Table 2). These patients were older (66.89 \pm 6.64 years) with the mean duration of longer aortic clamping $(98.72 \pm 31.72 \mathrm{mn})$ (Table 3 ). 
Table 1: Post-operative period.

$>$ All our patients (37 patients) were admitted to the Intensive Care Unit, intubated, ventilated and sedated for a few hours, with a monitoring of the various parameters (Hemodynamic, Respiratory, and Biological).

$>$ Post-operative wake-up:

- Calm: 25 patients $(67.56 \%)$

- Agitation: 09 patients $(24.32 \%)$

- Disorientation: 02 patients $(05.40 \%)$

- Presence of motor deficit: 02 patients $(05.40 \%)$ revealing ischemic cerebral vascular accident (CT scans).

$>$ Extubation: (H: Hour)

- $\leq$ H8 postoperative: 09 patients $(24.32 \%)$

_ H8-H12 postoperative: 13 patients (35.13\%)

- $\quad$ H12-H24 Post-operative: 11 patients (29.73\%)

_ H24 postoperative: 02 patients $(5.40 \%)$

02 patients $(5.40 \%)$ were never extubated because they died (Low cardiac output, multivisceral defects syndrome).

Table 2: Results of the MMSE.

\section{Loss $\geq 2$ points suggests a cognitive disorder.}

Results of MMT: Of the 33 patients; comparison of results between pre-op / post-op (The difference)

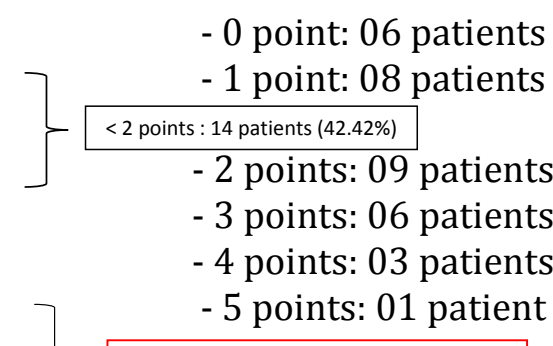

$\geq 2$ points : 19 patients $(57,57 \%)$

- Memory (3 words): 19 patients (100\%)

- Calculation-Attention : 14 patients $(73.68 \%)$

- Orientation (time-space) : 07 patients (36.84\%)

- Practice : 03 patients $(21.05 \%)$

Table 3: Analysis of risk factors.

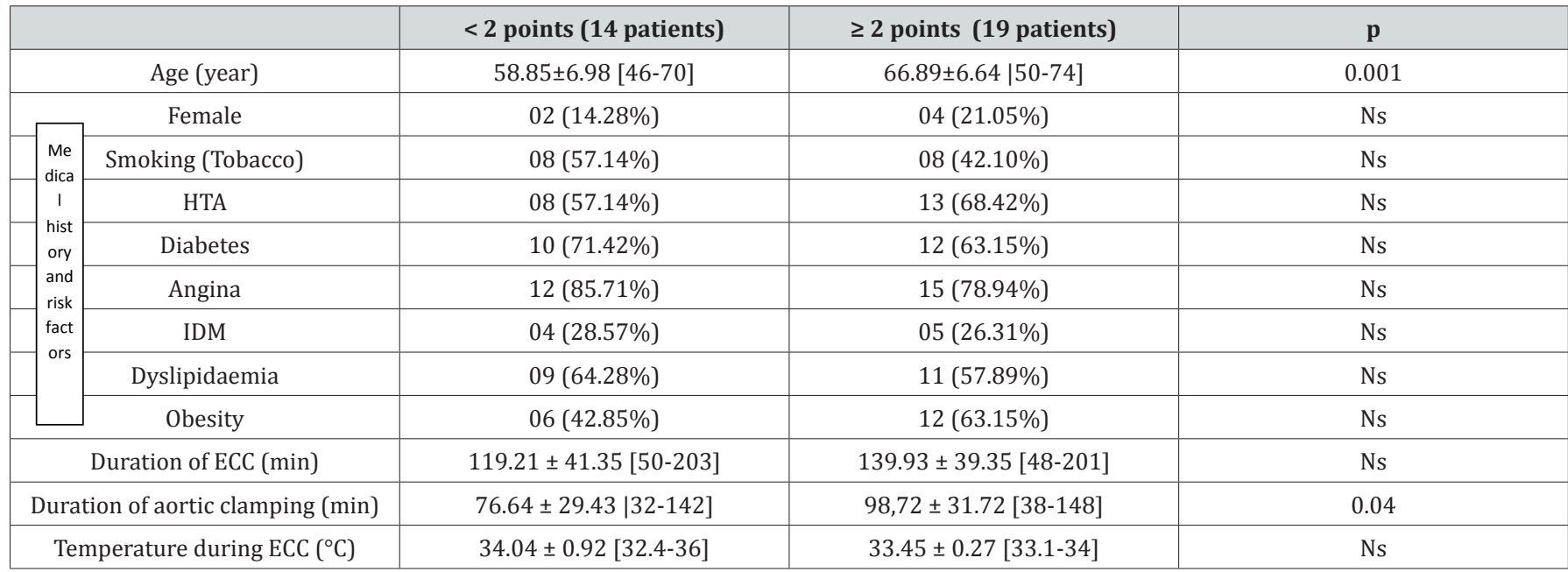




\begin{tabular}{|c|c|c|c|}
\hline Vasoactive Drugs & $06(42.85 \%)$ & $13(68.42 \%)$ & Ns \\
\hline Postoperative hematocrit (\%) & $29.42 \pm 2.79 \mid 24-34]$ & $28.88 \pm 3.51[23-36]$ & Ns \\
\hline
\end{tabular}

ECC: Extracorporeal circulation.

Ns: Not significant

\section{Discussion}

Cardiac surgery (valvular or coronary) is a well documented risk factor for postoperative cognitive disorders [3]. The most affected population concerns the oldest patients, benefiting from the longest ECC. These data corroborate those of the literature in this field $[5,6,13]$. The embolic mechanism is considered to be the main provider of neurocognitive disorders during this surgery, whereas cerebral hypoperfusion, in particular per-CEC, or inflammation, probably play only a minor role. Microemboles less than $40 \mu$ in diameter composed of platelets, leukocyte clusters, air, fat and particles from the CEC circuit [14-16] would disrupt self-regulation of cerebral blood flow, making it more sensitive to changes in mean arterial pressure [17]. These debris would be released at the time of aortic cannulation, clamping and clamping, proximal suture of the venous graft and at each aortic manipulation. These microemboli are easily visualized by the transcranial doppler [15].

These phenomena of microembolism would be more important in the case of valvular surgery than coronary surgery [5]. The aggravating role of too rapid warming after hypothermic CEC and postoperative hyperthermia has been well documented. Recent evidence suggests, however, that inflammation may favor deterioration of cognitive performance after coronary bypass surgery [18].

In cardiac surgery where the embolic mechanism remains predominant, materials to reduce the occurrence of intraoperative stroke (arterial filters) have proved to be ineffective. On the other hand, a not too rapid warming during the use of a normothermic $\mathrm{CEC}$, the postoperative temperature control with the systematic use of antipyretics, the immediate treatment or even the prevention of episodes of complete arrhythmia by atrial fibrillation are all recommendations that can be formulated [19].

For appropriate management of these patients, it is interesting to create networks of care in partnership with neuropsychologists, which will enable the development of therapeutic strategies for the management of these patients. It would be useful to create protocols to detect these perioperative cognitive disorders (evaluation) and to propose a treatment regimen according to the symptoms described.

\section{Conclusion}

While improvements in the morbidity and mortality of cardiac surgery patients have been achieved through improved surgical, anesthetic and resuscitation techniques, it remains that $30 \%$ to $80 \%$ of these patients capable of developing neurocognitive disorders that are mostly functional, transient and of variable cause. These dysfunctions can sometimes persist for months, even years and seem to be a factor of comorbidity. Postoperative cognitive decline is associated with decreased quality of life for patients and significant social and financial implications for these patients and their families. It is important to be able to assess the baseline cognitive status of these patients before surgery. An easy-to-use, rapid, reproducible, and readily available scale in patients' beds seems to us to be a wise option to allow for a rapid, albeit rough, assessment of the cognitive status of these patients. Prevention of post-operative cognitive impairment requires the identification of individuals at risk and must be one of the objectives of anesthesia consultation.

In total, the Mini Mental State Examination (MMSE) is a practical tool for screening and clinical follow-up of the cognitive state of patients by the clinician. It's simple use makes it a test that deserves to be included in the systematic review of patients operated in cardiac surgery. It is, however, only a test for cognitive impairment.

\section{Referencces}

1. Blackstone EH (2000) Neurologic injury form cardiac surgery-an important but enormously complex phenomenon. J Thorac Cardiovasc Surg 120: 629-631.

2. Ahonen J, Salmenperä M (2004) Brain injury after adult cardiac surgery Acta Anaesthesiol Scand 48(1): 4-19.

3. Newman MF, Grocott HP, Mathew JP, White WD, Landolfo K, et al (2001) Report of the substudy assessing the impact of neurocognitive function quality of life 5 years after cardiac surgery. Stroke 32(12): 2874-2881.

4. Van Dijk D, Keizer AMA, Diephuis JC, Durand C, Vos LJ, et al. (2000) Neurocognitive dysfunction after coronary artery bypass surgery: a systematic review. J Thorac Cardiovasc Surg 120(4): 632-639.

5. Ebert AD, Walzen TA, Huth C, Hermann M (2001) Early neuronal disorders after cardiac surgery: a comparative analysis of coronary artery bypass graft surgery and valve replacement. J Cardiothorac Vasc Anesth 15: 15-19.

6. Arrowsmith JE, Grocott HP, Newman MF (1999) Neurologic risk assessment, monitoring and outcome in cardiac surgery. J Cardiothorac Vasc Anesth 13(6): 736-743.

7. Moller JT, Cluitmans P, Rasmussen LS, Houx P, Rasmussen H, et al. (1998) Long term postoperative cognitive dysfunction in the elderly ISPOCD1 study. ISPOCD investigators international study of postoperative cognitive dysfunction. Lancet 351(9106): 857-861.

8. Ahlgren E, Lundqvist A, Nordlund A, Aren C, Rutberg H (2003) Neurocognitive impairment and driving performance after coronary artery bypass surgery. Eur J Cardiothorac Surg 23(3): 334-401.

9. Selnes OA, Mc Khann GM (2005) Neurocognitive complications after coronary bypass surgery. Ann Neurol 57(5): 615-621.

10. Weissrock S, Levy F, Balabaud V, Thiranos JC, Dupeyron JP, et al. (2005) Interest of the mini mental state examination to detect cognitive defects after cardiac surgery. Ann Fr Anesth Reanimation 24(10): 1255-1261. 
11. FolsteinMF, Folstein SE, McHugh PR (1975) Mini-Mental State. A practical method for grading thecognitive state of patients for the clinician. Jpsychiat Res 12(3): 189-198.

12. Newman S, Stygall J, Hirani S, Shaefi S, Maze M (2007) Postoperative cognitive dysfunction after non cardiac surgery: a systematic review. Anesthesiology 106(3): 572-590.

13. Andrew MJ, Baker RA, Bennetts J, Kneebone AC, Knight JL (2001) A comparison of neuropsychologic deficits after extracardiac and intracardiac surgery. J Cardiothorac Vasc Anesth 15(1): 9-14.

14. Nussmeier NA (2002) A review of risk factors for adverse neurologic outcome after cardiac surgery J. Extra Corpor Technol 34(1): 4-10.

15. Clark RE, Brillman J, Davis DA, Lovell MR, Price TR, et al. (1995) Microemboli during coronary artery bypass grafting. Genesis and effecton outcome. J Thorac Cardiovasc Surg 109(2): 249-257.

16. Roach GW, Kanchuger M, Mangano CM, Newman M, Nussmeier N, et al. (1996) Adverse cerebral outcomes after coronary bypass surgery.

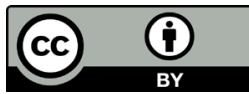

This work is licensed under Creative Commons Attribution 4.0 License

DOI: $10.19080 / J A I C M .2017 .04 .555647$
Multicenter Study of Perioperative Ischemia Research Group and the Ischemia Research and Education Foundation Investigators. N Engl J Med 335(25): 1857-1863.

17. Newman MF, Croughwell ND, Blumenthal JA, White WD, Lewis JB, et al. (1994) Effect of aging on cerebral autoregulation during cardiopulmonary bypass. Association with postoperative cognitive dysfunction. Circulation 90: 243-249.

18. Kalman J, Bogats G, Babik B, Rimanoczy A, Janka Z, et al. (2006) Elevated levels of inflammatory biomarkers in the cerebrospinal fluid after coronary artery bypass surgery are predictors of cognitive decline. Neurochem Int 48(3): 177-180.

19. Grigore AM, Grocott HP, Mathew JP, Phillips-Bute B, Stanley TO, et al (2002) The rewarming rate and increased peak temperature alter neurocognitive outcome after cardiac surgery. Anesth Analg 94(1): 4-10.

\section{Your next submission with Juniper Publishers} will reach you the below assets

- Quality Editorial service

- Swift Peer Review

- Reprints availability

- E-prints Service

- Manuscript Podcast for convenient understanding

- Global attainment for your research

- Manuscript accessibility in different formats

( Pdf, E-pub, Full Text, Audio)

- Unceasing customer service

Track the below URL for one-step submission https://juniperpublishers.com/online-submission.php 